\title{
Development of children's early understanding of numeric structure
}

\author{
Marina Vasilyeva ${ }^{\mathrm{a}, \mathrm{b}^{*}}$, Elida Laski ${ }^{\mathrm{a}}$, Aleksandr Veraksa ${ }^{\mathrm{b}}$, Chen Shen ${ }^{\mathrm{a}}$ \\ a Lynch School of Education, Boston College, Boston, USA \\ ${ }^{\mathrm{b}}$ Faculty of Psychology, Lomonosov Moscow State University, Moscow, Russia \\ *Corresponding author. E-mail: marina.vasilyeva.1@bc.edu
}

\begin{abstract}
Understanding of the base-10 structure of multi-digit numbers is one of the critical aspects in early mathematics learning. It has been documented that children from different countries vary in their use of base-10 representations. Questions concerning potential sources of this variability have been debated for decades. One commonly posited explanation is that some languages provide explicit cues about the structure of multi-digit numbers, facilitating the development of base-10 representations. In the present study, we tested this view against an alternative view, positing that variability in children's learning of numeric structure may reflect differences in their experiences with numbers. The study examined kindergartners and first-graders from four countries: Taiwan, South Korea, the USA, and Russia. Results showed that the use of base-10 representations by American first-graders increased dramatically over the last decades, following changes in curricular guidelines. First-graders across the four countries showed some differences in performance (however, not consistent with the language account), whereas kindergartners performed comparably despite the differences in their languages. The results suggest that the nature of early math instruction may be critical for children's developing understanding of numeric structure.
\end{abstract}

Keywords: mathematics learning, numeric system, numeric representations, cross-national study, kindergartners

\section{Introduction}

\section{Early conceptual development in mathematics: Understanding base-10 structure}

The significance of children's development of mathematical understanding for their subsequent academic and professional success has been well established (e.g., Aubrey, Godfrey \& Dahl, 2006; Jordan, Kaplan, Ramineni, \& Locuniak, 2009). In particular, a strong basis in mathematics is critical for success in a variety of scientific 
and technological disciplines. One of the questions debated over the years concerns the educational approach that would lead to optimal learning of mathematics during the early years of schooling, when the foundations of future knowledge are being built. Both researchers and educators have emphasized that early math skills should be acquired in a meaningful way-not simply by memorizing a set of numeric facts and procedures, but rather by connecting the learning of these facts and procedures to a conceptual understanding of numbers and numeric relations (Byrnes \& Wasik, 1991; Hiebert, 2013).

One of the critical conceptual developments in early mathematics concerns understanding of the hierarchical base-10 structure of the numeric system, i.e., the idea that a multi-digit number is composed of ones, tens, hundreds, etc. (e.g., Geary, 2006). It is believed that knowledge of the base-10 structure facilitates accurate problem-solving (Fuson \& Briars, 1990). In particular, when children solve arithmetic problems mentally, their choice of efficient computational strategies can be predicted by their base-10 knowledge (Laski, Ermakova, \& Vasilyeva, 2014). Consider, for example, a double-digit addition problem, such as $45+23$. When solving this problem, decomposition (e.g., $45+23=(40+20)+(5+3)=68)$ offers a more efficient and less error-prone strategy than counting on (e.g., $45+23=\ldots 46,47$, $48,49, \ldots 68)$. The choice of decomposition strategy depends in part on how children represent the two-digit addends. Those who are able to represent a number as a combination of tens and ones (e.g., 45 is four tens and five ones) should be more likely to apply decomposition, compared to those who do not think about numbers in terms of their base-10 structure, but rather tend to represent them as collections of single units.

Before formal schooling, most children think of numbers larger than 10 as collections of units rather than as groups of tens and ones (Mix, Prather, Smith, \& Stockton. 2014). It takes several years for children to develop an understanding of the base-10 system and place-value notation (Fuson, 1992; Fuson \& Briars, 1990; Varelas \& Becker, 1997). Yet the dynamics of acquiring this foundational aspect of mathematical knowledge appear to vary across cultural and educational backgrounds. In particular, research conducted almost 30 years ago suggested that American children lag behind their counterparts from East Asian countries, such as China, South Korea, and Japan, in performance of tasks that require understanding of the base-10 structure (Miura, 1987).

One task that is commonly used to assess children's understanding of the base10 structure is a block task (e.g., Miura, Okamoto, Kim, Steere, \& Fayol, 1993), in which children are asked to "show" two-digit numbers using blocks that include small cubes representing single units and bars that represent 10 units combined together. If children think of numbers as collections of single units, they will represent a number, such as 32 , using 32 individual unit cubes. If, however, children understand the base-10 structure of numbers, they are more likely to do so using three ten-bars and two individual units. When this task was presented to first-graders from the US and Japan, the Japanese children were more likely to use base-10 representations (combinations of ten-bars and single units), whereas their American counterparts tended to use only single unit cubes to represent the same numbers (Miura \& Okamoto, 1989). 


\section{Potential sources of differences in children's understanding of base-10 structure}

Given the significance of children's conceptual understanding of the hierarchical numeric structure for future math learning, it is important to explore potential sources of the observed differences in the acquisition of this concept. One explanation that emerged in prior work posits that it is the nature of the numeric language that may facilitate or impede children's understanding of the structure of multidigit numbers. The idea is that number words in some languages, such as Chinese, contain explicit cues about the hierarchical base-10 structure of the numeric system. For example, the literal translation of the Chinese word for 11 is "ten-one", 12 is "ten-two", 20 is "two-ten", 35 is "three-ten five", and so on. Thus, the wording reveals and possibly draws attention to the base-10 structure of multi-digit numbers. In contrast, number words in languages such as English and Russian do not provide as clear base-10 information about the number, possibly putting these children at a disadvantage in learning about numeric structure.

Even though the language account appears to provide a logical explanation for the differences originally found when comparing American and Asian students, it is important to disentangle the role of linguistic factors from the role of other cultural and educational factors associated with mathematics learning. While there is clear variability among linguistic systems in number naming, there is also variability in educational contexts that may affect learning (Perry, 2000; Stigler \& Stevenson, 1992). In other words, it is possible that differences in educational experience, rather than (or in addition to) language-based numeric representations, account for the differences in students' understanding of the base-10 structure. It is particularly useful to understand the extent to which instruction may affect this phenomenon because, unlike language features, school instruction is a factor that can be changed based on the evidence of best practices.

Consider potential differences in curricular approach that may facilitate or impede the use of base-10 representations on the block task. Some instructional systems may introduce children to the concept of hierarchical organization of the numeric system and may use activities, such as counting by tens or decomposing two-digit numbers into tens and ones, early on in classroom instruction. Others may focus initially on mastering simple number facts (such as single-digit addition) and counting by ones. Furthermore, the use of base-10 decomposition strategy in arithmetic calculations is likely to have a bi-directional relation with children's understanding of the base-10 structure. On the one hand, as shown in prior work, children who have a better conceptual understanding of the structure of multi-digit numbers are more likely to use a decomposition strategy in arithmetic (Laski et al., 2014). On the other, repeated practice using this strategy may solidify children's understanding of the numeric structure. Thus, explicit discussion of the base-10 structure and emphasis on using the base- 10 decomposition strategy may facilitate growth of students' base-10 knowledge.

\section{The present study}

The present study was designed to investigate the role of educational experience, in comparison to language, in the development of children's number representa- 
tions. As a basis for our investigation, we took Miura's (1987) experimental task, in which children were asked to represent two-digit numbers with single units and ten-blocks. Our goal was to determine how the use of base-10 representations varied with the math experience, as well as language, of participating students. The participants were recruited from the USA, Russia, Taiwan, and South Korea. English speakers are commonly compared with speakers of Asian languages when examining linguistic factors related to math performance. The inclusion of Russian students provided a comparison case that was particularly relevant to the present investigation due to the characteristics of mathematics instruction in Russian elementary schools, as well as the features of the Russian counting system that are less transparent than in Asian languages.

Because the present study was focused on the potential role of instruction, it is important that the instructional approaches in the four countries-Russia, Taiwan, South Korea, and the US - vary in notable ways. The approach used in some Russian elementary schools, including those that participated in the present study, emphasizes the mastery of basic computational skills at the early stages of math instruction, as well as children's ability to solve word problems that involve simple math facts. In contrast, much of the effort in the initial elementary instruction in Taiwan and South Korea is focused on developing a concept of number, understanding the structure of number and the ways in which numbers relate to each other. US instruction has undergone substantial changes over the years, with the focus shifting from the mastery of number facts to a deeper understanding of numeric structure, as discussed below. Taking into consideration the variability in both linguistic and instructional environments across the four participating countries, we aimed to determine whether children's performance in our study was more consistent with the linguistic or instructional account. Towards that goal, we addressed several research questions.

Have students' numeric representations changed over time, following changes in instructional practices? Examining trends in children's cognitive performance over the past decades can be useful for understanding underlying mechanisms of development. For example, the discovery of the Flynn effect (generational increase in IQ scores) highlighted the role of environmental factors in the growth of intellectual functioning (Flynn, 1987). In the present study, we were interested in determining whether cross-national differences in base- 10 representations observed 25 years ago (Miura, 1987) would be reproduced in the performance of contemporary students. While numeric language has remained constant over this period of time, mathematics instruction in the US has undergone substantial changes (Hiebert, 2003; National Research Council, 1989, 2001; Rampey, Dion, \& Donahue, 2009). These changes were in part stimulated by research revealing American students' weaknesses in understanding key mathematical concepts (National Research Council, 2001). As indicated above, the current curricular guidelines emphasize the need for developing a better understanding of the numeric system, including the base-10 structure of multi-digit numbers. If the pattern of cross-national differences in performance on number representation tasks has changed over time, it would underscore the role of instruction in the development of base-10 representations.

Are cross-national differences in kindergartners who have limited instructional experience parallel to those in first-graders? Most studies reporting lin- 
guistic effects on children's number representations have relied on data obtained with first-graders (Miura, 1987; Towse \& Saxton, 1997). However, math performance in first grade may reflect, at least in part, effects of instruction. This view is supported by a study of Japanese students, which showed increased use of base-10 representations by first-graders compared to same-aged kindergartners (Naito \& Miura, 2001). In the present study, we examined cross-national patterns in firstgraders as well as kindergarten students. Kindergartners present an interesting case for cross-national comparison, because they are proficient speakers of their language, who have a numeric vocabulary that extends beyond the first 10 numbers; yet, their exposure to math instruction is more limited than that of first-graders. Our preliminary interviews with teachers indicated that by the time of the study, kindergartners in all four nations were familiar with two-digit numbers, but only in the context of rote counting routines.

If the tendency of Asian students to use base-10 representations is largely driven by the features of their language, then we should expect Asian kindergartners to show this tendency. While younger children may be less accurate in reading numbers or counting blocks, the relative use of base-10 representations should be higher in kindergartners speaking more transparent languages. If, on the other hand, math instruction plays the key role in developing base-10 representations, two predictions can be made: (a) kindergarten students in each country should be less likely to use such representations than first-graders, and (b) cross-national differences among kindergarten students should be smaller than among those in first grade.

Furthermore, given their limited experience with two-digit numbers, kindergartners may be affected by the type of practice they receive on the number representation task. Saxton and Towse (1998) argued that English-speaking first-graders in their study may have lacked experience with number tasks and, therefore, were particularly sensitive to the experimenter's demonstration during practice trials. If this is true, then kindergartners, including those from Asian countries, may also perform differently depending on the type of practice provided. Thus, in the present study we examined the performance of first grade and kindergarten students in two practice conditions: one involving single-digit numbers only (where the experimenter modeled only single unit representations) and the other involving both single and two-digit numbers (where a base-10 representation was modeled by the experimenter).

Is performance affected by the transparency of number words or by children's experience with numbers? As discussed above, the Korean and Chinese languages have a number system that captures the base-10 structure for any number above 10. English and Russian are less numerically transparent languages, and the degree of transparency varies across numbers. Consider, for example, the word for the number 12. In Mandarin, the word is "shi-er", which literally means "tentwo". Similarly, in Korean, the word is "ship-yi", which also means "ten-two". In Russian, the word is "dvenadtsat" or "two-on-dzat" (where "dzat" is an archaic word that in the distant past meant "ten", but has not been used in modern language as a separate word with this meaning). Finally, in English, the word is "twelve", which contains the least number of clues about the composition of the number as two and 10. Yet, for larger numbers, the base-10 structure becomes more transparent in both English and Russian. Thus for example, "61" sounds like "liu-shi-yi" (six- 
ten-one) in Mandarin, "yook-ship-il" (six-ten-one) in Korean, "shestdesyat odin" (six-ten-one) in Russian and "sixty-one" (six-ty-one) in English.

In the present study, we selected target numbers so that their names varied in terms of the explicitness of the base-10 structure. A linguistic account suggests that English- and Russian-speaking children may be more likely to generate a base-10 representation for more transparent than for less transparent targets (e.g., "sixtyone" versus "twelve"). If, on the other hand, children's number representations are largely shaped by mathematical experience, one would expect a different pattern. As children tend to have more experience with smaller numbers, they may have a better idea about " 12 " as a quantity comprised of one ten and two single units and thus may be more likely to produce base-10 representations for smaller, than for larger, numbers.

\section{Method}

First grade and kindergarten students were given the same number representation task with two-digit numbers. Half the students were tested in the single-digit practice condition, and the other half in the mixed-digit practice condition. During test trials, students were allowed to show the number any way they wanted. This task provided a window into how children spontaneously think about two-digit numbers-i.e., whether the first type of representation that comes to their minds involves a combination of tens and ones or a collection of ones.

\section{Participants}

The study included a total of 598 students: 272 kindergarten students and 326 firstgraders. The US sample was recruited from suburban schools (public and private) in the state of Massachusetts. The Korean sample was recruited from public and private schools in a suburb of Seoul. The Russian and Taiwanese samples were recruited from public schools in the capitals-Moscow and Taipei, respectively. The participants from all four countries attended schools in districts that served families from middle- and upper-middle-class backgrounds. Table 1 presents the number and characteristics of participants from each country.

Table 1. Sample characteristics by grade and country

\begin{tabular}{lccc}
\hline \multicolumn{1}{c}{ First Grade } & Number of students & $\begin{array}{c}\text { Mean age in months } \\
\text { (age range) }\end{array}$ & $\begin{array}{c}\text { Percentage of female } \\
\text { students }\end{array}$ \\
\hline USA & 93 & $86(77-96)$ & $52 \%$ \\
Russia & 113 & $91(82-101)$ & $50 \%$ \\
Taiwan & 60 & $88(81-98)$ & $53 \%$ \\
S. Korea & 60 & $86(82-92)$ & $58 \%$ \\
& & Kindergarten & \\
USA & 90 & $73(61-84)$ & $57 \%$ \\
Russia & 60 & $81(68-89)$ & $50 \%$ \\
Taiwan & 62 & $76(68-81)$ & $47 \%$ \\
S. Korea & 60 & $73(67-80)$ & $50 \%$ \\
\hline
\end{tabular}




\section{Materials}

Materials in this study included a set of plastic blocks that consisted of small cubes (unit-blocks), each representing a single unit, and longer bars (ten-blocks) with the 10 single-unit segments marked, as shown in Figure 1. Thus, one ten-block was equivalent to 10 unit-blocks. At the start of the study, 100 unit-blocks and 20 tenblocks were placed in separate trays.

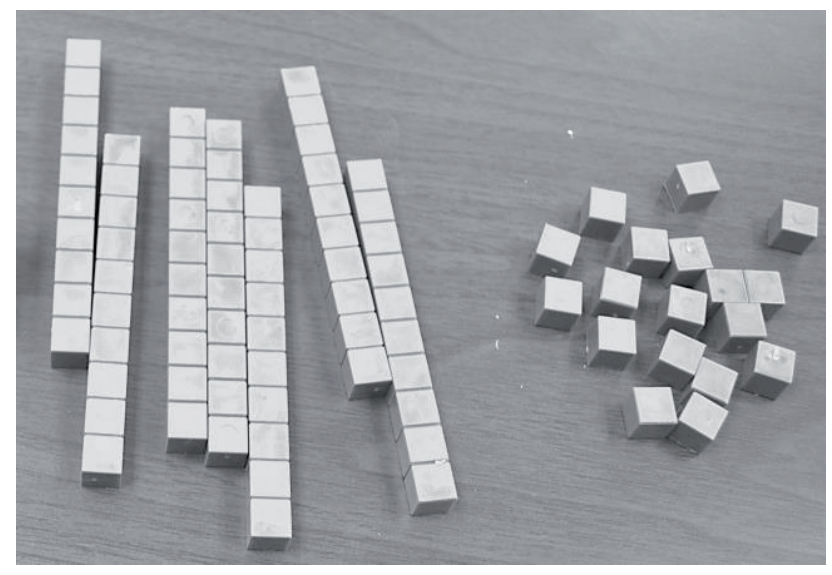

Figure 1. Materials used in the block task

Materials included numeral cards that were printed on heavy construction paper; each card was $10 \mathrm{~cm}$ x $10 \mathrm{~cm}$ in size and displayed a single number printed in the middle of the card. Three cards were used for the practice trials (the numbers 2,7 , and 14). Depending on the practice condition, children were presented either with the cards showing the numbers 2 and 7 or with the cards showing the numbers 2 and 14 . Five cards were used for the test trials (12, 16, 28, 34, and 61). These numbers were chosen because they represent a range of tens and ones, and also because they afford different degrees of transparency of numeric structures.

\section{Procedure}

Children across countries and grade levels were tested following identical procedures, which consisted of an introduction phase, followed by two practice trials and five test trials.

Introduction. The tester pointed to the trays with unit- and ten-blocks which were placed on the table in front of the child, and explained that these blocks could be used to show numbers. The child's attention was drawn to the fact that there were different kinds of blocks and that the long one was the same as 10 small ones. To demonstrate this, the tester took one ten-block and 10 single unit-blocks from the trays and lined up the unit-blocks against the ten-block while counting from 1 to 10 .

Two practice trials. The introduction was followed by practice trials, during which the tester presented the child with a number card (e.g., 7), saying: "Now, I'll show you how we can make this number using the blocks". The tester 
chose the appropriate number of blocks and placed them next to the card, saying, "Look, this shows 7 [pointing to the card] and this shows 7 [pointing to the blocks]". Students in each classroom were randomly assigned to either the singledigit or mixed-digit condition. In the single-digit condition, children received practice trials with the numbers 2 and 7 , which were constructed by the tester using unit-blocks. In the mixed-digit condition, children received practice trials with numbers 2 and 14. To represent 14, the tester used one ten-block and four unit-blocks.

Five test trials. The practice was followed by test trials. In each trial, children were presented with a number card (e.g., 12) and were told that now they had to show the number using the blocks. They were given an empty tray on which the number representation was to be created. The five number cards $(12,16,28,34,61)$ were presented in random order to each child. After the child finished constructing the number representation from blocks, the response was documented on the answer sheet. The tester recorded how many blocks of each kind (single-unit- and ten-blocks) the child used to represent a given number. Further, the tester wrote comments to describe particular features of the child's response (e.g., whether the child arranged blocks in a certain shape or made comments that could be helpful in coding).

Coding of responses. Number representations constructed by children during test trials were categorized based on a coding scheme that captured the nature of the children's responses. This scheme was partly based on prior work that had distinguished three categories: canonical and non-canonical base-10 representations, and single unit collections (Miura, 1987; Saxton \& Towse, 1998). A response was coded as a "canonical base-10 representation" if the child used the largest possible number of ten-blocks to represent the tens in the two-digit number and used single unit-blocks to represent the ones. For example: 12 would be represented with one ten-block and two unit-blocks; 28 would be represented with two tenblocks and eight unit-blocks, etc. A response was coded as a "non-canonical base10 representation" if the child used some ten-blocks (but not the maximum possible quantity) and more than nine unit-blocks. Such a strategy could be used only on trials with target numbers 28,34 , and 61 . For example, 28 could be represented with one ten-block and 18 unit-blocks, 34 could be represented with two tenblocks and 14 unit-blocks, etc. A response was coded as a "single-unit representation" if the child used only single-unit blocks to represent the entire number. For example, 12 would be represented with 12 unit-blocks and 61 would be represented with 61 unit-blocks.

In addition to these three categories, based on performance observed in our study, we added two more types of representations that did not fit into previously described categories. One of them was "unit confusion: no distinction between tens and ones". This category was used when the child either used ten-blocks to represent the ones or unit-blocks to represent the tens in the target number. For example, number 12 could be represented with 12 ten-blocks, each supposedly standing for a single unit. Even more interestingly, the child could represent the number 12 with three unit-blocks: one of them was placed separately to represent 10 (as evidenced from the child's comment), while the other two blocks were placed at another spot 
on the tray, each representing a single unit. Another category observed in children's performance was a "shape-based representation", in which the child depicted the shape of each numeral with the blocks rather than representing the quantity. For example, the number 12 could be drawn using single unit-blocks to show the form of " 1 " and " 2 ". These two categories were relatively rare, but coding them allowed us to capture a fuller range of strategies used at different grade levels.

Finally, children's responses that did not fit into any of the above five categories were coded as "other". This category also included guesses (when the child grabbed a random number of unit-blocks and placed them on the tray in a pile, without counting) and non-responses. This category included some extremely rare strategies that comprised less than $0.5 \%$ of all responses, such as representing the number " 28 " with three ten-blocks and then covering with a figure two single units within one of the blocks to arrive at 28 .

\section{Results}

\section{Representational accuracy}

We began our analysis by examining whether children were able to accurately name the target number shown on the card, which indicated the extent of their familiarity with two-digit numbers. Such familiarity can be viewed as a prerequisite for solving our block task. Indeed, a child who cannot name any of the numbers presented in the test cannot be expected to accurately represent the quantity corresponding to that number. Our examination showed that first-graders were $99 \%$ correct in naming the numbers presented to them and kindergartners were, on average, $94 \%$ correct. Figure 2 depicts naming accuracy results by country and grade. Note that even though kindergartners were less accurate than first-graders, their accuracy levels were still very high-90\% and above in each country. Furthermore, there were no children in either age group who named more than two numbers incorrectly, indicating that the participants were sufficiently familiar with the written representation of two-digit numbers.

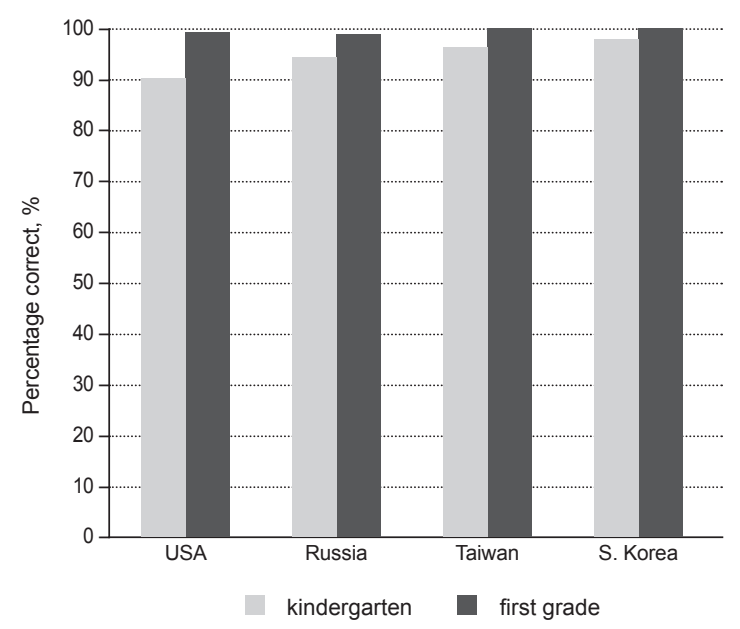

Figure 2. Accuracy in naming numbers 
In the next step, we examined how accurately children were able to represent the quantity corresponding to the target number using the blocks. A response was considered correct if the value of the blocks used by the child added up to exactly the number shown on the card (regardless of the kind of representation used). For example, if 28 was represented with 28 single units or one ten-block and 18 single units, it was coded as correct, but if 28 was represented with 23 single units or one ten-block and eight single units, it was coded as incorrect. The results are presented in Figure 3. A 4 (Country) $\times 2$ (Grade) ANOVA, with the accuracy of representations across five trials as the dependent variable, produced a single significant finding: a main effect of grade, $F(1,590)=53.77, p<.001, \eta_{p}{ }^{2}=.08$, with first-graders producing more accurate representations than kindergartners (98\% and $82 \%$ correct, respectively).

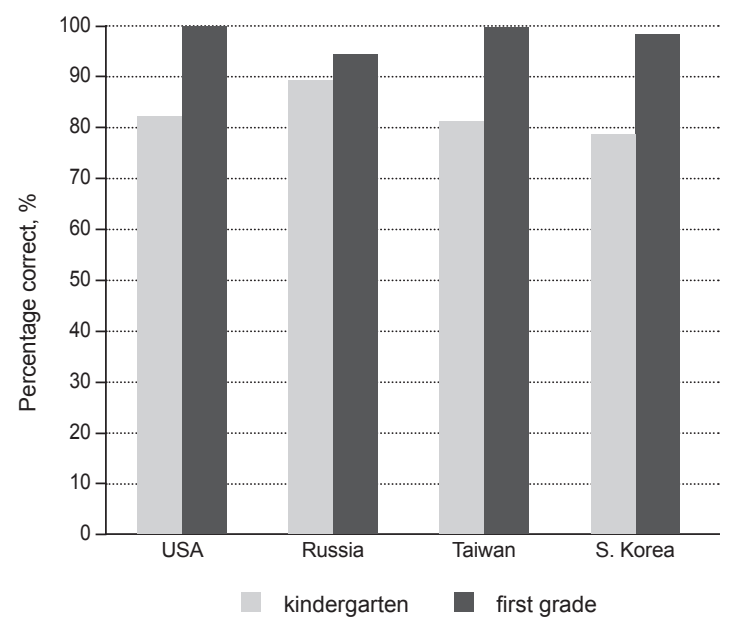

Figure 3. Accuracy in representing numbers

About a quarter of all errors (26.5\%) were due to inaccurate counting (e.g., when a child who used only unit-blocks double-counted some of them and as a result represented 61 with 59 blocks). In contrast to such "mechanical" counting errors, other errors reflected conceptual difficulties with the task, when children chose inappropriate representational strategies-for example, using unit-blocks to represent tens. Below we examine in-depth children's performance on the block task, investigating potential factors affecting their ability to create appropriate representations of numbers.

\section{Representational strategies}

The main focus of our analysis was on the types of number representations constructed by the children. Table 2 illustrates the different ways in which children in the current study represented two-digit numbers, as well as the frequencies of each type of representation. Consistent with previous studies, we found that the most common types of representations across the four countries were canonical base- 10 and single-unit. At the same time, important differences emerged in the current findings, relative to those of earlier studies. 
Table 2. Percentage of representations in each category (across the two practice conditions)

\begin{tabular}{|c|c|c|c|c|c|c|}
\hline & $\begin{array}{c}\text { Canonical } \\
\text { base-10 }\end{array}$ & $\begin{array}{l}\text { Non-canon- } \\
\text { ical base- } 10\end{array}$ & $\begin{array}{l}\text { Single unit } \\
\text { collection }\end{array}$ & $\begin{array}{l}\text { Unit confu- } \\
\text { sion }\end{array}$ & $\begin{array}{l}\text { Shape- } \\
\text { based }\end{array}$ & Other \\
\hline \multicolumn{7}{|c|}{ First grade } \\
\hline USA & 90 & 1 & 9 & 0 & 0 & 0 \\
\hline Russia & 75 & 4 & 16 & 2 & 2 & 1 \\
\hline Taiwan & 98 & 0 & 2 & 0 & 0 & 0 \\
\hline S. Korea & 95 & 1 & 4 & 0 & 0 & 0 \\
\hline \multicolumn{7}{|c|}{ Kindergarten } \\
\hline USA & 48 & 8 & 30 & 2 & 9 & 3 \\
\hline Russia & 56 & 7 & 28 & 2 & 3 & 4 \\
\hline Taiwan & 57 & 7 & 19 & 6 & 3 & 8 \\
\hline S. Korea & 53 & 3 & 27 & 7 & 3 & 7 \\
\hline
\end{tabular}

Changes in students' number representations over time. Table 3 indicates a frequent use of canonical base-10 strategies in American first-graders. This finding suggests a change in performance over the 25 years since the original crossnational research on number representations (Miura, 1987). It should be noted, however, that the studies by Miura and colleagues only included a single-digit practice condition, whereas our study also included a mixed-digit condition. To make a more accurate comparison, we computed the percentage of different strategies used by our participants in the single-digit condition only. Table 3 presents data for the comparison of the two studies. These data reveal changes in performance over time, even when using a parallel procedure and participants from comparable backgrounds. The use of base-10 representations has increased in all three countries, but the most dramatic change has occurred in the performance of American first-graders.

Table 3. Percentage of base-10 and single-unit representations used by first graders: Comparison across studies

\begin{tabular}{lccc}
\hline & Canonical base-10 & Non-canonical base-10 & Single unit collection \\
\hline USA & \multicolumn{3}{c}{ Miura et al (1988) } \\
China & 8 & 1 & 91 \\
S. Korea & 81 & 9 & 10 \\
& 83 & 11 & 6 \\
\hline USA & & Present study (2013) & 18 \\
Taiwan & 81 & 1 & 3 \\
S. Korea & 96 & 1 & 7 \\
\hline
\end{tabular}

Notes. Results for the present study are from the single-digit practice condition, which is parallel to the condition used in Miura's (1988) study. Chinese participants in that study and Taiwanese participants in the present study were speakers of Mandarin. 
Differences across grade levels. Comparing responses of first grade and kindergarten students, we made several observations. First, the use of base-10 representations was more frequent among first-graders than kindergartners, whereas the use of single-unit collections showed the inverse pattern (see Table 2). Further, in addition to using base-10 and single-unit representations, kindergartners used a range of erroneous strategies, albeit infrequently. For example, some students reproduced the shape of the target number, despite having had two practice trials in which blocks were used to represent numerical values. Others did not fully understand the value of ten- and unit-blocks, using them interchangeably. In contrast to kindergartners, first-graders in three of the four countries did not use erroneous representations.

We conducted a 2 (Grade) $\times 4$ (Country) $\times 2$ (Practice Condition) ANOVA, with the percent of canonical base-10 representations as the dependent variable. (Note that we ran two parallel analyses: one examining responses on all trials and the other considering only the trials where children produced accurate names and representations of target numbers. The pattern of results was the same. Statistics reported here are based on all trials.) We found main effects of grade, $F(1,582)=155.10, p<.001, \eta_{p}{ }^{2}=.21$, country, $F(3,582)=3.92, p=.009, \eta_{p}{ }^{2}=.02$, and practice condition, $F(1,582)=75.29, p<.001, \eta_{p}{ }^{2}=.12$. These main effects were qualified by interactions between grade and country, $F(3,582)=5.95, p=.001$, $\eta_{p}^{2}=.03$, and between grade and practice condition, $F(1,582)=14.91, p<.001$, $\eta_{p}^{2}=.03$. (See Figure 4.)

Mixed-digit practice condition

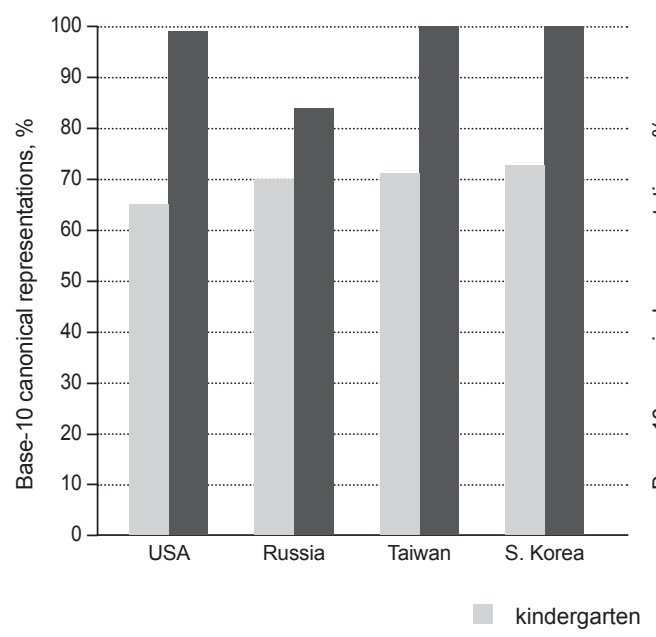

Single-digit practice condition

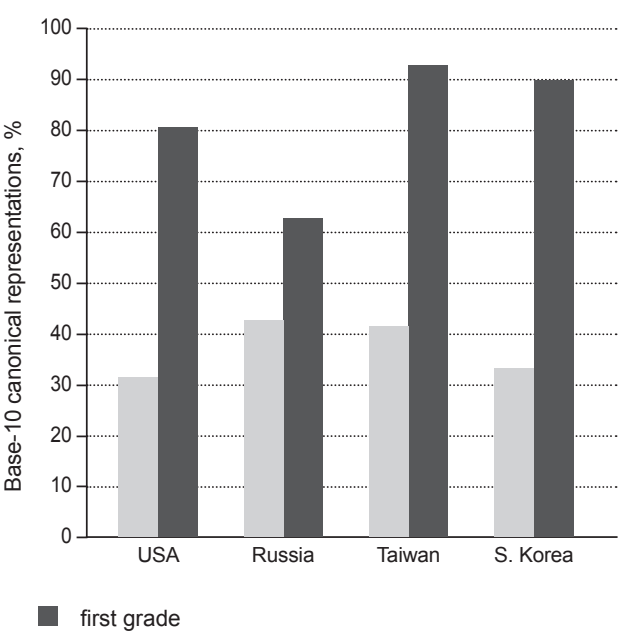

Figure 4. Use of base-10 canonical representations: Effects of grade, country, and condition

The effect of grade reflected our previous observation: kindergartners used canonical base-10 representations less frequently than first-graders (confirmed by pairwise comparisons by grade within each country, using Bonferroni correction, all $p$ 's $<.05)$. The interaction between grade and country was further investigated with tests of simple effects. The results showed no significant differences across countries among kindergartners, $F(3,264)=1.70, p=.17, \eta_{p}{ }^{2}=.01$, but a significant 
difference among first-graders, $F(3,318)=10.15, p<.001, \eta_{p}^{2}=.10$. To examine differences among first-graders by country, we conducted pairwise comparisons using the LSD method. The results showed that the effect of country was driven by Russian first-graders, who used canonical base-10 representations less frequently than their peers in other countries, who were not different from each other. The interaction between grade and practice condition was examined with tests of simple effects. They showed a more frequent use of base-10 canonical representations after mixed-digit practice compared to single-digit practice in both grades, but the effect was more pronounced among kindergartners, $F(1,264)=73.57, p<.001, \eta_{p}{ }^{2}=.20$, than among first-graders, $F(1,318)=12.48, p<.001, \eta_{p}^{2}=.05$.

In sum, the findings most relevant to our research questions indicated that: (a) kindergarteners showed no differences across countries; (b) American first-graders performed comparably to peers from Taiwan and South Korea, whereas Russian first-graders used base-10 representations less frequently; and (c) practice affected performance in both grades, but most strongly in kindergarten.

Patterns of performance with different numeric magnitudes. To examine how students' performance varied with the target number, we conducted a 5 (Number) $\times 2$ (Grade) $\times 4$ (Country) ANOVA, with the percentage of canonical base10 strategies as the dependent variable. We found significant effects of number, $F(4,590)=18.4, p<.001, \eta_{p}{ }^{2}=.03$, and grade, $F(1,590)=138.3, p<.001, \eta_{p}{ }^{2}=.19$, as well as an interaction between them, $F(4,590)=13.5, p<.001, \eta_{p}{ }^{2}=.02$. Simple effects tests revealed that target number did not affect the use of base-10 representations in first-graders, $F(4,322)=.60, p=.66, \eta_{p}{ }^{2}=.003$. In contrast, it impacted the performance of kindergarten students, $F(4,271)=31.40, p<.001, \eta_{p}{ }^{2}=.07$. The average frequency of using base-10 representations varied across target numbers in the kindergarten sample as follows: $62 \%$ of responses with " 12 ", $59 \%$ with " 16 ", $53 \%$ with " 28 ", $46 \%$ with " 34 ", and $43 \%$ with " 61 ". Critically, country did not interact with number, so the overall pattern observed in kindergartners was the same across countries. For example, in the US sample, kindergarten students used base10 representations on $59 \%$ of trials with " 12 " and $46 \%$ of trials with " 61 ". In the Taiwanese sample, kindergarteners used base-10 representations on $65 \%$ of trials with " 12 " and $42 \%$ of trials with " 61 ". In summary, in all participating countries, the frequency of creating base-10 representations among kindergartners decreased as the magnitude of the target numbers increased.

\section{Discussion}

The present study examined the early development of children's understanding of the base-10 number structure, which has been shown to play a significant role in their subsequent learning of mathematical concepts and procedures. To address this issue, we compared the use of base-10 representations by kindergartners and first-grade students from four countries. In contrast to the long-standing view that cross-national variability in math achievement may be due to language differences, such as the transparency of the base-10 structure in number words (Fuson \& Kwon, 1992; Geary, Bow-Thomas, Liu \& Siegler, 1996), we hypothesized that the differences may reflect variations in instructional emphases.

We tested this hypothesis in several ways. First, conducting the study 25 years after the original data were collected provided an opportunity to explore potential 
changes in students, following a period of changes in math instruction. Second, examining performance of both first grade and kindergarten students provided another way of separating language and instructional effects by testing children who spoke the same language but differed in experience. Third, by varying practice conditions and the transparency of number words, we were able to further evaluate the extent to which performance was driven by language features versus children's experience with numbers.

\section{Changes in students' performance over time}

The striking changes observed in the responses of American first-graders on the number representation task, relative to earlier findings (Miura, 1987), indicate that performance on this task is sensitive to experiential factors. The last few decades in the US have witnessed an on-going debate about the goals of mathematical education (National Research Council, 1989; Schoenfeld, 2004). The debate has spurred substantial revisions of mathematics curriculum aimed at increasing instructional support for the development of conceptual understanding of numbers and numeric relations (National Council of Teachers of Mathematics, 1989, 2000, 2006). Our results suggest that changes in curricular content that have occurred during the last decades may have contributed to changes in children's thinking about the base- 10 structure of multi-digit numbers.

To be clear, we are not making general claims about the quality of American math education. Our analyses focused on a specific aspect of conceptual development in the early school years. Our participants were not representative of the entire student population-as in the earlier studies, they were from well-educated professional families. Further, as the math curriculum in the United States is determined by local school districts within broad state guidelines, the experience of our participants may differ from that of other students in the country. We would argue, however, that this does not pose a challenge with respect to our goal of evaluating the role of instruction, in comparison to language, in the development of numeric representations. Uncovering changes in American students that have occurred over time is directly relevant to this goal. Our findings indicate that English-speaking first-graders are able to perform equivalently to speakers of more transparent languages when representing the base-10 structure of numbers, even though past studies revealed a different pattern of performance.

\section{First-graders' use of base-10 representations across four countries}

In all participating countries, first grade students were highly accurate in naming two-digit numbers and representing them with unit- and ten-blocks. Further, first-graders most often represented numbers using the canonical base-10 strategy. Thus, by the time of the study, these students had developed a high level of understanding of the base-10 structure of two-digit numbers. The language-based prediction (whereby Korean and Taiwanese children would produce base-10 representations more frequently than American and Russian students) was not supported by the data: American students did not differ from their Asian peers in this regard. The one group that differed from the others was Russian first-graders, who used base-10 representations less frequently (although it was still the prevalent way of representing numbers), which could be due to differences in math instruction. 
Although a detailed curriculum analysis was outside the scope of this paper, our examination of curricular guidelines and instructional materials led us to make some observations. We found that in those schools from which Russian participants were recruited, the instructional emphasis in the first half of the year was primarily on the development of computational skills within 10, and then within 20. Most activities involved arithmetic exercises and computational word problems, although there were also some measurement activities that could have promoted the understanding of base-10 structure, such as conversion of centimeters into decimeters (e.g., $14 \mathrm{~cm}=1 \mathrm{dm}+4 \mathrm{~cm}$ ). The Russian teachers indicated that the bulk of activities that focus directly on the structure of two-digit numbers and place value usually follow the period when initial computation skills are established. If our study had compared the ability to solve word problems across participating countries, it is quite likely that the Russian first-graders would have shown the highest level of performance. But since the study compared the use of base-10 representations, for which Russian participants had received less instruction at the beginning of first grade, it is not surprising that their use of such representations was somewhat less frequent.

The experience of study participants from the other three countries was different in that a major emphasis of early instruction was on the systematic understanding of single- and two-digit numbers, including their magnitude and place value. Toward this goal, teachers used a variety of activities. For example, we observed American students in some of the classrooms counting how many days had passed since the start of the school year. On the first day, students put a straw in the "ones" pocket on the wall display. They continued adding straws daily until arriving at 10, at which point the straws were bundled together and placed in the "tens" pocket. This and other activities were clearly designed to facilitate the understanding of the base-10 numeric structure.

A potential concern could be that if some of these activities included unit- and ten-blocks, the students in our study may have used them mechanically to reproduce what they did in class. We determined that some first-graders were indeed exposed to manipulatives similar (but not identical) to the ones included in this study. However, this factor alone did not appear to predict the frequency of base-10 representations. Taiwanese teachers reported using these materials, Korean teachers did not use them at all, and American teachers differed in this respect, yet their students showed statistically equivalent results.

\section{Development of number representations in kindergarten students}

Given that first-graders had some instructional activities involving two-digit numbers, we were particularly interested in determining whether kindergartners would show differences in number representations consistent with the linguistic explanation. These children arguably had more limited practice with two-digit numbers than first-graders (although they still might have diverse numeric experiences through parental input or earlier instruction). Our examination of curriculum guidelines and interviews with teachers indicated that instructional activities involving two-digit numbers were not introduced until first grade in all participating countries. Kindergartners were expected to recognize two-digit numbers and include them in their counting routines, but there was no class instruction on place value (tens and ones), and no activities that required decomposing two-digit numbers into tens and ones. 
Lack of cross-national differences. Our results confirmed kindergarten students' familiarity with two-digit numbers, as they were highly accurate in naming them. At the same time, kindergartners used base- 10 representations less frequently than first-graders-the pattern seen in all four countries. Critically, there were no significant differences in the use of base-10 representations among kindergartners across countries, despite the fact that they were familiar with the required numeric language and the languages varied in transparency of the base- 10 structure. The lack of differences by country cannot be explained by a floor effect, because kindergartners produced base- 10 representations on about half of the trials, with substantial variability within each country. In fact, the use of these representations did vary systematically, albeit not as a function of language, but as a function of practice condition and target number.

Practice effects. Like first-graders, kindergartners used more base-10 representations following mixed-digit, compared to single-digit, practice. The effect was even stronger in kindergarten students, indicating that they were particularly influenced by observing the use of a ten-block during practice. A possible explanation of the practice effect is that it reflected imitation rather than a genuine understanding of base-10 structure. However, we believe this explanation is unlikely. Only a small percentage of students (1.3\%) seemed to use ten-blocks to imitate the experimenter: They produced single-unit collections combined with a ten-block (e.g., $12=12$ unit-blocks +1 ten-block, $34=34$ unit-blocks +1 ten-block) on multiple trials. Yet the majority of students who used base-10 representations did so in a meaningful way, choosing the appropriate number of ten-blocks, rather than mechanically reproducing the use of one ten-block, as observed in practice. Our findings are consistent with those of Saxton and Towse (1998), who also concluded that an increased use of base-10 representations following a mixed-digit practice is not attributable to imitation.

To offer a possible explanation for the observed effect of practice, we turn to Siegler's overlapping waves theory, which posits that at any given time, children have multiple ways of thinking about a problem (Siegler, 1996). They select among possible approaches based on their prior experience and the likelihood that a given approach will efficiently lead to an accurate response (Shrager \& Siegler, 1998). In this context, some kindergartners and most first-graders may have access to different ways of representing numbers, including single unit collections and a more efficient base- 10 representation. The latter may become more prominent as children gain experience with two-digit numbers, leading them to a better understanding of underlying numeric structure. When the base-10 representation is a predominant way of thinking about numbers, children may use it spontaneously, regardless of whether it was used by the experimenter. However, at the earlier stages of forming a base-10 representation, children may require additional support to select it. This may explain why in the present study kindergartners across the four countries relied on such support more than first-graders.

Number effects. Variability in students' performance as a function of target number provided further evidence that the relative strength of particular representational strategies may depend on students' experience. We found that kindergartners in all four countries used base-10 representations more frequently with smaller numbers than with larger numbers. This result could not be explained by language features-in two languages (Mandarin and Korean) numbers did not vary 
in the degree of transparency, and in the other two languages (English and Russian) larger numbers actually had a more transparent base-10 structure. Yet the amount of experience with target numbers most likely did vary in a way corresponding to the observed pattern (i.e., more experience with smaller numbers). It is possible that children develop base-10 representations in an incremental way, starting with familiar, smaller numbers. For example, counting objects may help them realize that a set of 10 items needs two more to make 12. Thus, in addition to unit representations that arise earlier from counting objects up to 10, a fledgling base-10 representation may emerge as a way of thinking about some two-digit numbers. As children's experience expands, they accumulate more exemplars of two-digit numbers, leading to a more general mental representation of their base- 10 organization. If this is the case, children might acquire base- 10 concepts incrementally, first with two-digit numbers and later with three-digit numbers, rather than acquiring it all at once-an issue that should be investigated in future work.

\section{Limitations and future directions}

Converging evidence from different parts of our investigation indicates that instructional emphases (rather than, or in addition to, language factors) may play a critical role in the development of mathematical thinking. Yet, the present study did not involve a systematic observation of class instruction, which limited our ability to identify specific experiences that may promote the development of number representations in students. Our examination of curricular guidelines and informal interviews with teachers led to some speculation, but it would be important in future research to directly investigate the link between mathematical experiences and the development of this important aspect of numeric understanding. In particular, it might be useful to recruit Russian participants from schools using different curricular approaches to teaching early math. It should be noted that unlike 20 or 30 years ago, when the Russian educational system was guided by centralized policies, the current situation has become more decentralized, with school districts varying in the types of textbooks and curricular approaches. Based on the examination of the diverse instructional guidelines and the observation of classroom practices, researchers can formulate hypotheses as to which program is more likely to facilitate the development of numeric understanding. These hypotheses can then be tested by comparing performance on the base-10 tasks of students exposed to different curricula.

When comparing the performance of students receiving different types of instruction, it would be useful to expand the measures used to test children's mastery of base-10 concepts. The current investigation used only a block task. Future studies could examine this issue using a wider range of tasks, such as reading and writing multi-digit numbers. Examining correlations across a range of tasks, all of which require some understanding of the base-10 structure, will provide a more comprehensive picture of children's numeric knowledge.

Further, we recognize that our study focused on only one aspect of conceptual development, identified as an important part of the early foundation of mathematical learning. Clearly, there are numerous other concepts that children must develop, as well as procedural skills that should be mastered in order to solve math problems efficiently and accurately. Future studies focusing on specific aspects of conceptual development and procedural skills may allow investigators to pinpoint 
the areas that require targeted revisions of curricular and instructional approaches to teaching mathematics. These studies would benefit from including children even younger than the participants in the present study, because the foundations of numeric knowledge start developing prior to kindergarten. When looking at younger children, one can investigate their emerging intuitive understanding of numbers and numeric relations. This knowledge may be instrumental in designing instructional practices that expand on children's early notions of number and lead to the development of a more sophisticated understanding of the numeric system.

\section{Acknowledgements}

The work was supported with a grant from the Russian Scientific Fund (project № 16-18-00073).

\section{References}

Aubrey, C., Godfrey, R., \& Dahl, S. (2006). Early mathematics development and later achievement: Further evidence. Mathematics Education Research Journal, 18(1), 27-46. doi: 10.1007/BF03217428

Byrnes, J. P., \& Wasik, B. A. (1991). Role of conceptual knowledge in mathematical procedural learning. Developmental Psychology, 27(5), 777. doi: 10.1037/0012-1649.27.5.777

Flynn, J. R. (1987). Massive IQ gains in 14 nations: What IQ tests really measure. Psychological Bulletin, 101, 171-191. doi: 10.1037/0033-2909.101.2.171

Fuson, K. C. (1992). Issues in place-value and multidigit addition and subtraction learning and teaching. Journal for Research in Mathematics Education, 21, 273-280. doi: 10.2307/749525

Fuson, K. C., \& Briars, D. J. (1990). Using a base-ten blocks learning/teaching approach for firstand second-grade place-value and multidigit addition and subtraction. Journal for Research in Mathematics Education, 180-206. doi: 10.2307/749373

Fuson, K., \& Kwon, Y. (1992). Korean children's understanding of multidigit addition and subtraction. Child Development, 63, 491-506. doi: 10.2307/1131494

Geary, D. C. (2006). Development of mathematical understanding. In W. Damon \& R. M. Lerner (Series Eds.) \& D. Kuhn \& R. S. Siegler (Vol. Eds.), Handbook of child psychology: Volume 2: Cognition, perception, and language (6th ed., pp. 777-810). Hoboken, NJ: Wiley.

Geary, D. C., Bow-Thomas, C. C., Liu, F., \& Siegler, R. S. (1996). Development of arithmetical competencies in Chinese and American children: Influence of age, language, and schooling. Child Development, 67(5), 2022-2044. doi: 10.2307/1131607

Hiebert, J. (2003). What research says about the NCTM Standards. In J. Kilpatrick, W. G. Martin, $\&$ D. Schifter (Eds.), A research companion to principles and standards for school mathematics (pp. 5-23). Reston, VA: National Council of Teachers of Mathematics.

Hiebert, J. (2013). Conceptual and procedural knowledge: The case of mathematics. Routledge.

Jordan, N. C., Kaplan, D., Ramineni, C., \& Locuniak, M. N. (2009). Early math matters: kindergarten number competence and later mathematics outcomes. Developmental psycho$\log y, 45(3), 850$. doi: 10.1037/a0014939

Laski, E. V., Ermakova, A., \& Vasilyeva, M. (2014). Early use of decomposition for addition and its relation to base-10 knowledge. Journal of Applied Developmental Psychology, 35(5), 444-454. doi: 10.1016/j.appdev.2014.07.002

Miura, I. T. (1987). Mathematics achievement as a function of language. Journal of Educational Psychology, 79, 79-82. doi: 10.1037/0022-0663.79.1.79

Miura, I. T., Kim, C. C., Chang, C., \& Okamoto, Y. (1988). Effects of language characteristics on children's cognitive representation of number: cross-national comparisons. Child Development, 59(6), 1445-1450. doi: 10.2307/1130659 
Miura, I. T., \& Okamoto, Y. (1989). Comparison of US and Japanese first-graders' cognitive representation of number and understanding of place value. Journal of Educational Psychology, 81, 109-113. doi: 10.1037/0022-0663.81.1.109

Miura, I. T., Okamoto, Y., Kim, C. C., Steere, M., \& Fayol, M. (1993). First graders' cognitive representation of number and understanding of place value: Cross-national comparisons: France, Japan, Korea, Sweden, and the United States. Journal of Educational Psychology, 85(1), 24. doi: 10.1037/0022-0663.85.1.24

Mix, K. S., Prather, R. W., Smith, L. B., \& Stockton, J. D. (2014). Young Children's Interpretation of Multidigit Number Names: From Emerging Competence to Mastery. Child Development, 85(3), 1306-1319. doi: 10.1111/cdev.12197

Naito, M., \& Miura, H. (2001). Japanese children's numerical competencies: Age-and schoolingrelated influences on the development of number concepts and addition skills. Developmental Psychology, 37(2), 217-230. doi: 10.1037/0012-1649.37.2.217

National Council of Teachers of Mathematics Commission on Standards for School Mathematics. (1989). Curriculum and evaluation standards for school mathematics. Reston VA: National Council of Teachers of Mathematics.

National Council of Teachers of Mathematics (2000). Principles and standards for school mathematics. Reston, VA: National Council of Teachers of Mathematics.

National Council of Teachers of Mathematics (2006). Curriculum focal points for prekindergarten through grade 8 mathematics. Reston, VA: National Council of Teachers of Mathematics.

National Research Council (1989). Everybody counts: A report to the nation on the future of mathematics education. Washington, D.C.: National Academy Press.

National Research Council (2001). Adding it up: Helping children learn mathematics. J. Kilpatrick, J. Swafford, and B. Findell (Eds.). Mathematics Learning Study Committee, Center for Education, Division of Behavioral and Social Sciences and Education. Washington, D.C.: National Academy Press.

Perry, M. (2000). Explanations of mathematical concepts in Japanese, Chinese, and US first and $5^{\text {th }}$ grade classroom. Cognition and Instruction, 18, 181-207. doi: 10.1207/ S1532690XCI1802_02

Rampey, B. D., Dion, G. S., \& Donahue, P. L. (2009). NAEP 2008 trends in academic progress (NCES 2009-479). Washington, D.C.: National Center for Education Statistics.

Saxton, M., \& Towse, J. N. (1998). Linguistic relativity: The case of place value in multi-digit numbers. Journal of Experimental Child Psychology, 69(1), 66-79. doi: 10.1006/jecp.1998.2437

Schoenfeld, A. (2004). The math wars. Educational Policy, 18(1), 253-286. doi: 10.1177/ 0895904803260042

Shrager, J., \& Siegler, R. S. (1998). SCADS: A model of children's strategy choices and strategy discoveries. Psychological Science, 9, 405-410. doi: 10.1111/1467-9280.00076

Siegler, R. S. (1996). Emerging minds: The process of change in children's thinking. New York: Oxford University Press.

Stigler, J. W., \& Stevenson, H. W. (1992). The learning gap: Why our schools are failing and what we can learn from Japanese and Chinese education. New York: Summit Books.

Towse, J. N., \& Saxton, M. (1997). Linguistic influences on children's number concepts: Methodological and theoretical considerations. Journal of Experimental Child Psychology, 66, 362-375. doi: 10.1006/jecp.1997.2389

Valeras, M., \& Becker, J. (1997). Children's developing understanding of place value: Semiotic aspects. Cognition and Instruction, 15(2), 265-286. doi: 10.1207/s1532690xci1502_4 